\title{
Biobank finances: a socio-economic analysis and review
}

Sally Gee ${ }^{1}$, Rob Oliver ${ }^{2}$, Julie Corfield ${ }^{3}$, Luke Georghiou ${ }^{1}$, Martin Yuille ${ }^{4}$

1, 4: The University of Manchester (1: Manchester Institute of Innovation Research, Manchester Business

School; 4: Center for Integrated Genomic Medical Research, Institute of Population Health)

2: Research and Development Directorate, Salford Royal Hospitals NHS Trust, Stott Lane, Salford M6 8HD UK

3: Areteva Ltd., BioCity, Pennyfoot Street, Nottingham NG1 1GF UK

\section{Corresponding author}

Martin Yuille

Center for Integrated Genomic Medical Research, University of Manchester

Stopford Building, Oxford Road, Manchester M13 9PT UK

E: martin.yuille@manchester.ac.uk 


\section{Abstract}

This socio-economic study is based on the widely-held view that there is an inadequate supply of human biological samples that is hampering biomedical Research Development and Innovation (RDI). The potential value of samples and the associated data is thus not being realized. We aimed to examine whether the financing of biobanks contributes to this problem and then to propose a national solution. We combined three methods: a qualitative case study; literature analysis; and informal consultations with experts. The case study enabled an examination of the complex institutional arrangements for biobanks, with a particular focus on cost models. For the purposes of comparison, a typology for biobanks was developed using the three methods. We found that it is not possible to apply a standard cost model across the diversity of biobanks and we found that there is a deficit in coordination and sustainability and an excess of complexity. We propose that coordination across this diversity requires dedicated resources for a national biobanking Distributed Research Infrastructure. A coordination center would establish and improve standards and support a national portal for access. This should be financed centrally by public funds, possibly supplemented by industrial funding. We propose that: a) sample acquisition continues to be costed into projects and project proposals to ensure biobanking is driven by research needs; b) core biobanking activities and facilities be supported by central public funds distributed directly to host public institutions; and c) marginal costs for access be paid for by the user. 


\section{Introduction}

The provision of annotated human biological samples is critical for the discovery, validation and use of biomarkers, for understanding disease processes and for the development and the adoption of stratified medicine (sometimes termed "precision medicine" or "personalized medicine"). A collection of such annotated samples is commonly termed a biobank [1]. Use of biomarkers enables individuals in a population to be stratified into sub-groups defined by life-time or imminent risk of disease, by diagnosis of disease sub-type, by efficacy of treatment and by outcome. These uses then enable disease prevention in populations and/or improved treatments for individuals. Biomarkers that have been developed as companion diagnostics (tests to identify patients' likely responses to drugs) can improve productivity in clinical trials, reduce attrition rates, speed product development, improve market share and/or support higher drug prices [2]. However, discovery of biomarkers is widely considered to require a coordinated "big science" approach [3]. This entails researchers in pharmaceutical, biotechnology and diagnostic companies, hospitals and public research bodies having access to large numbers (hundreds to tens of thousands) of well annotated, high quality samples [4] managed by biobanks. Such an approach is consistent with national policy, since government has recognized that maintaining access to cutting edge experimental facilities and services is essential to competitiveness [5].

Biobanking performs an important function in academic and industrial biomedical RDI. It has been identified as an activity of national strategic importance in the United Kingdom [6, 7]. However, the way biobanking is currently financed and organized no longer meets the needs of the research community, and the high potential value of annotated samples is not being realized: market and system failures are resulting in under-exploited opportunities, as has been noted [8]. Poste [3] has cited an NIH survey in 2009 which found $80 \%$ of 700 laboratories reported serious difficulty in obtaining standardized samples for biomarker research. This inadequate supply, taken with lack of coordination and excessive complexity in biobanking, is hampering biomedical RDI. 
The aim of the work reported here, from the Strategic Tissue Repository Alliances Through Unified Methods (STRATUM) project, is to recommend a viable cost-model for a national biobanking solution based on analysis of the organization, governance and processes for a spectrum of biobank types. We seek to define the "as is" situation using a qualitative case-study approach and then, based on this definition, propose the most cost effective way of organizing in the future. The proposals are restricted to financial arrangements: structure, coordination and governance arrangements are out of scope. 


\section{Methods}

A method was required:

1. To capture the heterogeneity of biobanking activities and increase understanding of the organization of biobanking in the UK.

2. To enable the identification of the main cost drivers (i.e. factors that can cause a change in the cost of an activity).

3. To compare institutional arrangements in a variety of biobanks and in a network, so as to provide insights into the costs and benefits associated with different organizational forms, financial and access arrangements.

4. To provide, in combination with existing research, an evidence base for recommending national solutions to overcome the problems currently associated with biobanking in the UK.

To meet these requirements a combination of three methods was used: a qualitative case-study methodology plus an examination of the literature on the economics of biobanking and the funding of research infrastructure (RIS) plus informal consultations with experts in the field. This three-fold approach facilitates an exploration of processes and effects, as well as the identification of contextual and interdependent factors. It can also reveal how biobanks change over time with respect to organization, activities, benefits and associated costs. By contrast, quantitative data alone cannot give an accurate picture of the organization, activities, benefits and costs associated with biobanking.

The empirical cases draw on both primary (semi-structured interviews supplemented by telephone and email discussions) and secondary (minutes; press releases; meeting minutes and other records; evaluations) data. In each case, interviews were held with senior managers, principal investigators and in some cases finance officers and funders. Background information was collected prior to and following interview. Interviewees were identified by STRATUM stakeholders and a one-page summary was shared with the main contact prior to interview, with a request to identify additional interviewees. 
To capture the heterogeneity of biobanking activities, it is necessary to use a consistent typology. However, generating a suitable, and accepted, typology of biobanks is problematic as the categories involved are ultimately artificial constructs and subject to reinterpretation by different members of the biobanking community. Yet, capturing some of the diversity in organizational forms facilitates an analysis of their main characteristics and how these are interrelated. This knowledge is critical for informing decisions on financing, governance and access arrangements for a national biobanking solution. The development of a biobank typology was undertaken with a view to specification of a national biobanking solution. It was undertaken iteratively (by considering the first case so as to help identify an appropriate second case etc.), through literature analysis and through consultations with experts (listed under Acknowledgements). 


\section{Results and discussion}

This section has three sub-sections: on research infrastructure, the development of a biobank typology and on the cases studied. Results in each sub-section are dependent on the combination of the three methods described in Methods.

\section{Research infrastructure}

A biobank can be understood as a type of research infrastructure (RIS) [9]. Typically, we refer to "infrastructure" as technical structures, physical components or interrelated systems underpinning a wide range of economic and social activities (e.g. roads, electrical grids, the internet). Infrastructures confer benefits to a wide range of organizations and act as a shared or public resource. A RIS comprises the facilities, resources and related services used by the scientific community to support knowledge creation and distribution. Notable features include their excellence (construction and maintenance are subject to peer review) and the requirement that they serve both internal and external users. RIS is well established in the physical sciences. The Organisation for Economic Co-operation and Development (OECD) introduced [10] the concept of RIS for the biological sciences in 2001 and EU Member States recognized the need for biological RIS in 2006 [11]. Today, the EU's RIS comprises 89 structures coordinated across multiple sites [12]. It is currently updating its RIS construction and maintenance roadmap [13]. In 2014 OECD examined [14] legal, governance, funding and access policy options for International Distributed Research Infrastructure (IDRIS).

Because subjects are distributed across geographical areas, biobanks are distributed across multiple geographical sites. Consequently, biobanking RIS is most usefully considered as a distributed RIS (DRIS) that requires coordination and is thus distinct from a large single-site facility RIS. Here we follow the practice of the EU Member States' forum on RIS [15] and use the term DRIS to refer to national biobanking DRIS, i.e. a national network of biobank nodes that can include disease-specific or tissuespecific networks. An international DRIS for biobanking is under construction in the EU [16]. 


\section{Typology of biobanks}

The purpose and scale of creating collections of human biological samples has evolved over time from small private "curiosity cabinets" to publicly-owned epidemiological study collections with millions of samples annotated ever more fully. International biobanking activities have expanded rapidly over the last two decades. In 2013, over 200 biobanks (58 in hospitals; 98 academic; 59 industrial) were licensed under the UK Human Tissue Act for research [17]. These represent only a sub-set of collections and facilities, since there is no definitive list of collections in the UK and a licensed institution may have more than one biobank holding more than one collection. Furthermore, some sample types (e.g. DNA) do not require a license. It has been often observed that biobanks are heterogeneous $[1,18,19,20,21,22]$ and, furthermore, terms are not used consistently in the literature, in part due to the distinct expertise of different authors.

While a typology cannot incorporate all real or possible variations between biobanks, most attempts suffer from the limitation that definitions do not always have discrete boundaries (e.g. how to define a "large" biobank). Many biobanks actually fall within more than one category for any specific typological classification (e.g. funding from multiple sources). Moreover, we found that all of the biobanks investigated continue to evolve over time, shifting across boundaries.

Building on published observations and incorporating the expertise from within the STRATUM project, we devised a classification system for biobanks. We have considered the large number of categories in the literature, reduced them and broadened them to facilitate our focus on financial arrangements. These categories (though somewhat ambiguous and open to re-negotiation) indicate the functional variety in biobanking operations. We specified five classification categories:

- Purpose, location and ownership

- $\quad$ Size, scale and scope

- Nature of contents 
- Financing arrangements

- Access arrangements

\section{Purpose, location and ownership}

Biobanks can be classified according to the stated purpose for their existence (and their perceived ongoing role, which, like the stated purpose, may also evolve).

Academic research: This classification is often focused on aspects of a specific disease, condition or population, at a molecular or cellular level. This category can include biobanks informed by hypothesisdriven studies designed to answer a specific research question, and biobanks for longitudinal and population-based studies, i.e. cross-sectional and prospective studies. Publicly funded biobanks may also collect surplus surgical samples, sometimes with donor blood samples. Such publicly (government or charitably) funded biobanks provide samples for academic and industrial research.

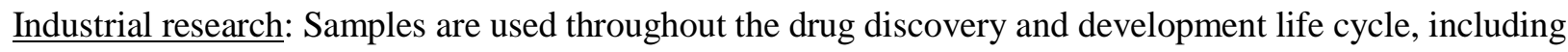
during target identification, target validation and as an essential part of safety and efficacy evaluation. Samples are also required in the development, testing and quality control of general and companion diagnostics to facilitate stratified or precision medicine. Samples are now often collected as part of clinical trials for biomarker and other studies.

Therapeutic purposes: Hospital pathology departments routinely archive samples obtained for diagnostic or therapeutic purposes. On-site or off-site archiving can be for a duration of 30 years or more. These samples may be suitable for research.

Teaching purposes: e.g. anatomical collections for medical education and training.

Commercial exploitation: a few biobanks have been constructed primarily for this purpose. Many commercial firms source samples either through clinical collaborations or by paying the appropriate fees 
to public biobanks in order to acquire specimens. Commercial biobanks may also be created with a view to bridging a gap in public funding, and therefore supporting the maintenance of sample collections.

The function of a biobank informs its ownership and location. A diverse range of institutions, organizations and groups own or manage biobanks, including government departments (e.g. Health, Defense, Justice), non-governmental organizations (including universities), charitable bodies, hospitals, and a variety of commercial organizations, such as pharmaceutical, biotechnology and sample sourcing firms. Gibbons notes [20] that the location and ownership of sample collections and data are not static characteristics: either may be changed for strategic and tactical reasons through collaborations and networking agreements. Relocation affects accessibility, if not de jure ownership [23].

Biobanks with different functional aims will have different institutional, governance and funding structures. They are also likely to vary in their access arrangements. For the purposes of this study, we include biobanks that have been constructed for academic research, pharmaceutical/biotech R\&D, and commercial exploitation, and therefore include biobanks in pharmaceutical firms, universities, hospitals and for-profit or cost-recovery organizations.

\section{Size, scale and scope}

The size, scale and scope of biobanking collections reflect the diversity of biobanking activities in the UK. Gibbons [20] defines size, scale and scope as the total number of samples; the quantity and extent of data; organizational structure (how many personnel, stakeholders, collaborators, sites, IT systems, networked datasets, and/or jurisdictions are involved); geographical spread; and participant population size. The size of the biobank may be a function of the purpose of the biobank and the host organization. Thus, a population biobank will involve samples from thousands of people, a biobank supporting research on a rare disease is likely to be smaller, and biobanks that serve more than one collector (and thus have at least one feature of a network) tend to be larger. 
For our analysis, networking is an important feature. Some partially networked biobanks have been established in the UK; these are usually based around disease or tissue types. All involve some type of common standards and aim to increase visibility and therefore access to samples. The oldest is the UK DNA Banking Network (UDBN) that evolved with common standards for consent, access, sample accrual and processing plus minimum sets of phenotypic data [24]. Similarly, the UK Stem Cell Bank implements common standards for stem cell lines [25]. The Motor Neurone Disease (MND) Association is accruing MND samples and data from patients seen at some 20 UK clinical centers, storing them centrally and enabling distribution by making the resources visible through the European Bioinformatics Institute's (EBI) European Genome-phenome Archive. The U-Biopred project in severe asthma (funded via the Innovative Medicines Initiative as a joint undertaking between the EU and industry) is based in approximately 20 clinical centers across the EU, and is managing a wide range of sample types from a single biobank using standard operating procedures and managing data using a single knowledge management system. The aim is to provide sample visibility and access for U-Biopred project members across academia and industry, as well as third parties in due course. The UK Brain Bank Network is implementing common standards across its biobank partners and implementing a web-based searchable catalogue of samples. The Confederation of Cancer Biobanks (CCB) also aims to increase the visibility of samples by providing information on the National Cancer Research Institute Biosample Directory, about samples held at member biobanks and as part of other collections. CCB also leads a harmonization project to improve quality and facilitate sample interoperability. The Breast Cancer Campaign Tissue Bank covers four sites that operate under shared guidelines and have a combined searchable catalogue. A project that started in 2015 led by University College London aims to construct a national searchable directory of samples [26]. This project will require elements of network construction and is supported by 26 mainly public funders.

In industry, biobanks are often established to support discovery strategies within the company for new molecular entities. Hence they are top-down in origin. By contrast, in the academic setting and public 
sector, biobanks frequently exhibit bottom-up conception and evolution, with research project funding for construction, as distinct from strategic funding for RIS. Although collections are increasingly associated with several research groups or with larger collection programs for multiple users, this has not removed the biobanking bottleneck in the delivery of stratified medicine [6]: a biobanking system has not been created at the national level in the UK.

Outside the UK there are efforts to pursue this goal, with projects for national systems underway in, for example, France and Germany. Across many EU Member States and Associated States, work has commenced [27] for an IDRIS - a pan-European network for coordination of biobanking, although the realization of cross-jurisdictional networks relies on some level of coordination within each jurisdiction $[28]$.

For the purposes of the current study, the cases represented include small collections, relatively large biobanks, and one evolving network. "Large" biobanks may provide economies of scale, as fixed costs decrease relative to the number of samples processed. Large biobanks may also have more formalized operational procedures and processes, including clear access and costing structures. Smaller collections can offer value and face different financial issues. There are lessons to be learned from each of these categories. Similarly, the experiences of an emerging national network offer insights into the organization and financing of a national DRIS. The age of a biobank is also relevant. Older biobanks are likely to have experienced different funding challenges and their experiences could provide valuable lessons. However governance practices may be less robust, sample quality more variable and annotated data may not have been maintained or updated. These characteristics have implications for the development of a national biobanking solution.

\section{Nature of contents}


Biobanks manage a wide variety of samples: different tissues, organs, body parts, body fluids, cell lines, and body waste products, as well as processed sub-fractions (derivatives) such as DNA, RNA and proteins.

The type of samples (and rationale for collection) has an impact on acquisition, storage/processing and distribution. Each of these factors is associated with varying costs. Samples (from healthy or diseased tissue) and donor type can influence the acquisition process, for example whether recruitment occurs through routine diagnosis and treatment or through specific interventional studies. Acquisition is also related to study design or biobank design (prospective and/ or retrospective; disease based; clinical trials etc.). Solids and liquids are stored in different formats and may require different storage conditions. Processing can also vary significantly. Conversely, the distribution of samples usually has minimal associated costs (relative to overall sample life cycle), although some samples, particularly fresh tissue, may require rapid transportation under specific conditions and therefore considerable costs may be incurred.

Annotations of samples have diverse sources. They can be drawn from a pre-existing database (e.g. electronic health/social care record; research databases containing individual research test results or environmental data) or introduced into a new database (e.g. an electronic lifestyle questionnaire or an electronic sample history database). Integrating diverse data sets is important for a national biobanking solution. Maintaining the annotations is essential to maintaining the scientific usefulness of the samples. Until relatively recently, all annotations were captured manually, and this could be associated with relatively high levels of human error and with significant cost implications. Samples can now be annotated from (or by linkage to) electronic databases, thus enabling longitudinal studies in real time. To optimize the research value of samples annotated in a network or a multicenter setting, it is critical to implement common ontologies for each type of data, including a sample history ontology. This is common within studies, but not across studies. Any system should also consider the potential for future European or international standardization. 
The case studies include biobanks with samples types collected in respiratory research. Some of these samples types are used in other areas of biomedical research: they may be termed "generic". However, we also included biobanks engaged in managing other materials in order that a case study might cast light on the provision of a national biobanking solution.

\section{Financing arrangements}

The financing arrangements and business models of biobanks vary. Typical UK funders include government departments, research councils, the National Health Service (NHS), academia, industry, and non-profit organizations including charities [29]. The majority of public (as distinct from commercial) biobanks rely on external "mixed" funding i.e. from a variety of sources. For publicly funded biobanks, this may include central government funding, charitable funding and discrete funds from companies, e.g. through access and service fees or ring-fenced (restricted use) funding for, say, research nurses. Biobanks located in industrial settings (including pharmaceutical companies) may be entirely financed through internal capital. In the case of "for-profit" biobanking firms, collections may initially be financed by venture capital, business angels or other sources of private capital. The majority of biobanking activities are maintained by ongoing public funding or, if in industry, through private finance or by acquisition of samples in return for a fee.

However, there is discussion (involving the scientific community, funders and policy makers) on the potential for biobanking to become self-sufficient, i.e. moving to a cost-recovery model. Although biobanks should not make financial gains from selling samples, gains are permitted from data about samples [30] or through the provision of services. See Box 1 for a range of views.

\section{Box 1 Financial gains from selling samples}

Selling samples for financial gains means making a profit (beyond operating costs including salaries) from trade in samples. This is a complicated area and not clearly prohibited, unlike, for example, the sale of organs for transplant.

- Cambon-Thomsen et al. note [31]: "The status of biological samples is initially an unresolved question; they can be considered to be either completely out of the commercial sphere as body 
parts, or not if they are covered by property rights... The issue of direct involvement of private companies in biobank projects may also create ambiguities regarding financial benefits derived from the use of free donation... biobanks intermingle notions of property shared by all of humanity with population and individual considerations. The participation of companies is more developed in terms of conditions of access to patients' samples and data. In case of benefits being generated, it is very unclear with whom and by which mechanisms they should be shared; various models have been proposed but even guiding principles remain unclear. This concept of benefit sharing must be balanced with the notion of 'public good' and population health that constitute biobanks".

- In the UK, the MRC states [32]: "The human body and its parts shall not, as such, give rise to financial gain. Researchers may not sell for a profit samples of human biological material that they have collected as part of MRC funded research, and research participants should never be offered any financial inducement to donate samples. Payment of reasonable expenses or costs is however acceptable".

- In the US, the University of California (SF) states similarly [33]: "Although UCSF banks and investigators are not allowed to sell specimens for profit, investigators involved in specimen banking are permitted to recover the costs within the UCSF re-charge system for expenses associated with collection, processing, storage, and distribution.”

Although a complex ethical and legal area, there is consensus that the public are more likely to donate if they know their research is publicly-funded and that it contributes to research with societal and medical benefits.

The Human Genome Organization Ethics Committee has adopted the principle [34] that researchers, institutions and commercial entities "have a right to a fair return for intellectual and financial contributions to databases." It also adopted the principle that "fees should not restrict the free flow of scientific information and equitable access." The public, including donors, could react against biobanking if a perception emerged that samples were being exploited for financial gain. In this context, many biobanks specify some form of access fee (alongside grant income) to maintain or support their operating activities, particularly if initial funding has been reduced or withdrawn.

We compiled a list of biobank revenue models from sources including reports from IBM on two World Wide Biobank Summits (cited in [19]) and from The Ecological Society of America [35]. Models identified were

- Centralized public funding for RIS

- Project funding from multiple sources 
- Charging membership or user fees

- Charging a tiered system of access fees differing between academia and industry

- Include RIS costs in all grants

- Creating endowments

- Collecting royalties on intellectual property

- Build fees into a product or service

- Associating RIS with existing institutions (fixed costs)

- $\quad$ Mixed models

These revenue models have implications for knowledge creation and innovation:

- The structure of membership and user fees could impact access.

- The inclusion of RIS costs in all grants requires coordination across projects and funding bodies.

- Collecting royalties on any resulting intellectual property risks increasing costs through royalty stacking [36]. Such risks are said to be particularly high in biotechnology [37].

- Associating RIS with an institution's fixed costs or with one main funder can result in inequity through free riding [38].

The case studies include biobanks that are funded by charities, central government, pharmaceutical companies and venture capital or private investment. Mixed models are seen in a few cases.

\section{Access arrangements}

Access to samples, data and services varies between biobanks. The level of access to a biobank has obvious implications for the scientific, social and economic impact of that biobank, as well as the potential to raise revenue from users. Three archetypal access models have been identified [20]:

- "Closed" or exclusive access. In this case, third parties could be excluded from using the data and samples collected.

- "Controlled" access by approved third parties, on application, and subject to conditions. This is the most common access arrangement for publicly funded and commercial biobanks. Biobanks internal to 
private companies work similarly. Access to the biobank is granted according to pre-defined criteria (e.g. type of user, type of research, type of sector, fields of use). This model can include the provision of services, so a biobank (or independent service provider) does not release samples to users but conducts the experiments and provides the resulting data. The latter, where applicable, has the benefit of conserving samples, may improve data quality and may ensure annotations are continually enriched, but may restrict analysis to specific technology platforms.

- "Open" or "public" access, possibly at a fee, that safeguards patient identifiers.

Greater user access directly increases the discovery and innovation potential of the infrastructure. Arguably, open access generates the highest number and widest variety of positive impacts (assuming sub-optimal use is minimized through some type of quality control). The more accessible the RIS, especially if operating with an obligation for users to update associated annotated data (where applicable and not commercially sensitive), the greater are the benefits. Indeed an open model where users are actively contributing - as in von Hippel and von Krogh's "Private-Collective" model [39] - has the potential to support a dynamic resource that increases in value over time. This increase in value has been termed an "enrichment effect" [18] that may be anticipated for a biobank network structure whose efficiency leads to a new generation of benefits. It has also been noted [18] that "copyleft" type solutions (where research results are granted back to a common pool) may both enrich annotations and reduce the risks of free riding and fragmentation of the resource.

However, a sample is ultimately a finite resource. Most biobanks are concerned with maximizing the research value of the samples that they manage. They agree that donated samples should be put to the "best possible use" meaning that access to finite samples should be granted according to the quality of a research proposal and the value of the expected outcomes. This model is widely accepted by the biobank and research community; as demonstrated by the creation of "access committees" to evaluate sample requests. There is clearly a balance between open access (more suited for data and knowledge) and controlled access (more suited for finite resources). Conversely, selling of access could conflict with the "best possible use" principle [30]. Questions on how to grant access, to whom, and whether and how to 
charge for this are clearly important.

The case studies include biobanks that have exclusive access (e.g. a pharmaceutical biobank), and controlled access (some with features of open access) policies. Access and financial arrangements are often related. Thus, the type of financing may affect the appropriation rules imposed on the network: public subsidies may imply open access [18].

\section{Case studies}

Eight cases were examined: seven biobanks and one network. A short description of each of these is provided in Supplementary Information. A full description is available on request. These descriptions were subject to the approval of respondents. The names given to these cases are: Abcodia; AZ biobank; Center for Integrated Genomic Medical Research (CIGMR) Biobank at the University of Manchester; Fresh tissue supply; Nottingham Health Sciences Biobank (NHSB); Small research collection; UK Biobank; UK Brain Bank Network (UKBBN). The cases were identified and interviewed between 2012 and 2013. Further details, including interview questions, are available in Supplementary Information. 
Table 1: Typology of cases

\begin{tabular}{|c|c|c|c|c|c|c|}
\hline $\begin{array}{ll}\text { Biobank } & \text { or } \\
\text { network }\end{array}$ & $\begin{array}{ll}\text { Location } & \text { and } \\
\text { ownership } & \end{array}$ & Purpose & Years & $\begin{array}{l}\text { Financing } \\
\text { arrangements }\end{array}$ & Access arrangements & Access Fees \\
\hline Abcodia & $\begin{array}{l}\text { University spin out } \\
\text { (venture capital, } \\
\text { private, university) }\end{array}$ & $\begin{array}{l}\text { Support the discovery and validation } \\
\text { of biomarkers }\end{array}$ & 2 & $\begin{array}{l}\text { Mixed public funds, } \\
\text { including charities, } \\
\text { venture capital, private }\end{array}$ & $\begin{array}{l}\text { Controlled access: by } \\
\text { access committee }\end{array}$ & $\begin{array}{l}\text { Flexible contractual and } \\
\text { financial arrangements }\end{array}$ \\
\hline AstraZeneca & $\begin{array}{l}\text { Corporate } \\
\text { (pharmaceutical) }\end{array}$ & $\begin{array}{l}\text { Support R\&D development of } \\
\text { personalised and other medicines and } \\
\text { companion diagnostics (exploratory } \\
\text { research; QC; storing clinical trial } \\
\text { samples) }\end{array}$ & $50+$ & Corporate & $\begin{array}{l}\text { Controlled access: } \\
\text { internal project review } \\
\text { or } \text { access committee }\end{array}$ & $\begin{array}{l}\text { No charge at point of } \\
\text { access: Free to internal } \\
\text { users; external access via } \\
\text { collaborations }\end{array}$ \\
\hline $\begin{array}{l}\text { CIGMR } \\
\text { Biobank }\end{array}$ & University & Supports genomic research & $12+$ & $\begin{array}{ll}\begin{array}{l}\text { Research } \\
\text { project grants }\end{array} & \text { council, }\end{array}$ & $\begin{array}{l}\text { Controlled access: by } \\
\text { technical committee } \\
\text { incl. original collector }\end{array}$ & $\begin{array}{l}\text { Tiered Access Fee: } \\
\text { Lower price for academics } \\
\text { Higher price for industry } \\
\text { users } \\
\text { Fee to cover distribution } \\
\text { not accrual } \\
\text { infrastructure }\end{array}$ \\
\hline Fresh Tissues & (project- & $\begin{array}{l}\text { Sourcing of fresh tissue for academic } \\
\text { and commercial research on-demand }\end{array}$ & 12 & $\begin{array}{l}\text { Biobank by NIHR via } \\
\text { Trust } \\
\text { Fresh tissue by projects } \\
\text { and contracts }\end{array}$ & $\begin{array}{lr}\text { Controlled } & \text { access: } \\
\text { collaborative } & \text { or } \\
\text { contractual } & \end{array}$ & $\begin{array}{l}\text { Tiered Access Fee: } \\
\text { Lower price for local } \\
\text { academics } \\
\text { Higher prices for industry } \\
\text { users }\end{array}$ \\
\hline NHSB & $\begin{array}{l}\text { NHS Trust university } \\
\text { hospital }\end{array}$ & $\begin{array}{l}\text { Supports translational and clinical } \\
\text { research }\end{array}$ & 2 & NHS Trust & $\begin{array}{l}\text { Controlled access: by } \\
\text { access committee }\end{array}$ & $\begin{array}{l}\text { Tiered Access Fee: } \\
\text { Lower price for local } \\
\text { academics } \\
\text { Higher price for industry } \\
\text { users } \\
\text { Fee to cover biobank and } \\
\text { trust overheads }\end{array}$ \\
\hline
\end{tabular}




\begin{tabular}{|c|c|c|c|c|c|c|}
\hline $\begin{array}{l}\text { Small } \\
\text { Collection }\end{array}$ & $\begin{array}{l}\text { University research } \\
\text { group and hospital }\end{array}$ & $\begin{array}{l}\text { Unspecified future disease orientated } \\
\text { research }\end{array}$ & 16 & Project grants & $\begin{array}{l}\text { Controlled access: ad } \\
\text { hoc }\end{array}$ & No charge \\
\hline UK Biobank & Independent charity & Unspecified prospective studies & $6+$ & $\begin{array}{l}\text { Mixed public funds, } \\
\text { including charities }\end{array}$ & $\begin{array}{l}\text { Controlled access: by } \\
\text { access committee }\end{array}$ & $\begin{array}{l}\text { Flat registration fee } \\
\text { Flat data access fee } \\
\text { Variable samples Access } \\
\text { Fee: } \\
\text { Fee to cover direct costs }\end{array}$ \\
\hline $\begin{array}{lr}\text { UK } & \text { Brain } \\
\text { Bank Network }\end{array}$ & University Hospital & Co-ordinate national brain banks & 4 & Research council & $\begin{array}{l}\text { Controlled access: by } \\
\text { access committee }\end{array}$ & $\begin{array}{l}\text { Aim to introduce a } \\
\text { standard access fee } \\
\text { Fee to cover distribution } \\
\text { not accrual or } \\
\text { infrastructure }\end{array}$ \\
\hline
\end{tabular}

Table 1 legend: Following the typology described in the text, the eight case studies are tabulated by Location and ownership; Purpose; Years since collection of samples began (or years since inception for Abcodia and UKBBN); Financing arrangements; Access arrangements; Access fees 
Their typologies are tabulated in Table 1 . These illustrate the diversity of biobanking activities in the UK. Most of the biobanks were affiliated with an existing institution and were located in public organizations, including universities and hospitals. This is consistent with a US National Human Genome Research Institute (NHGRI) survey finding [40] that "most biobanks are affiliated in one or multiple ways with other entities: $88 \%$ are part of at least one or more larger organizations (67\% of these are academic, $23 \%$ hospitals, $13 \%$ research institutes)". The survey also found that just 5\% of US biobanks were for-profit organizations and 7\% were incorporated. Although no similar survey has been conducted in the UK, our interviews indicate that the US ratios are comparable to those in the UK. Our case studies can be considered proportionally representative, capturing the majority of biobank types. An omission from our cases is the "virtual biobank" - an intermediary agent. Such agents do not manage samples, but, rather, they source them through a network for their clients. Human Focused Testing and Tissue Solutions [41] are two such intermediary agents.

One of the cases examined was an existing biobank network. UK Brain Bank Network provides coordination of access to samples from a specific organ. Networks like this tend to focus on disease areas or tissue types. The emergence of such networks indicates how sample collectors, users and managers may be self-organizing, aiming to address access and funding issues "from the ground-up".

We conclude that a national biobanking solution would need to integrate a heterogeneous population of organizations and emerging networks. There are challenges associated with this, including high management and coordination costs, and overcoming barriers to interaction as well as communication. There are also valuable benefits to be realized. These include:

- Increased visibility of and access to samples.

- Raised quality and comparability through the promotion of best practices. 
- Financial savings through pooling of resources.

- The potential to review and plan collections strategically.

- Optimized opportunities for knowledge creation (since knowledge creation and more radical innovation tend to occur at the intersection of disciplines and organizations).

The solution of a national biobanking DRIS would exhibit increasing network externalities (i.e. returns or benefits) as more biobanks join, more researchers contribute and more researchers use the DRIS. The construction of a national biobanking DRIS therefore requires that particular attention be given to the different operating modes and strategies of a diverse population of biobanks.

\section{Costs}

Respondents were asked to complete a questionnaire about initial set-up costs (refurbishment, freezers, other storage systems, automation, robotics, test equipment, IT and LIMS) and annual operating expenses (salaries, rental, facility maintenance, service charges, IT systems, equipment maintenance/servicing and consumables). Note that this questionnaire may be deployed elsewhere, perhaps in conjunction with the tool developed by an international panel [42].

The response rate and level of detail was variable between institutions and detailed, comparable data were not obtained. The reasons for this are:

- Cases had hidden costs and cross-subsidizing (e.g. services, resources or facilities were not solely attributable to the biobank but were shared or provided by a larger, over-arching organization).

- Cases had opaque financial systems, including complex models and accounting systems used by the NHS and Universities.

- Cases were unable to provide financial data (e.g. detailed figures were not prepared previously because in many cases there is no institutional or regulatory obligation to break down the figures relating to biobanking). 
- Cases were unwilling to provide financial data because of commercial or confidentiality considerations.

Where detailed figures were available, it emerged that these were not comparable for the following reasons:

- Differences between cases in samples types (e.g. figures provided by Nottingham Health Sciences Biobank indicated a six-fold variation in the cost of processing and biobanking samples of serum vs frozen fresh tissue).

- Different cases managed different stages of the samples life cycle (i.e. only a subset of all the processes that a biobank might undertake).

- Different cases used different cost calculation methods based on divergent definitions of full costs, direct costs, indirect costs and depreciation.

There are a number of other problems in obtaining fully comparable data. One arises from the various definitions of a "sample." In the case of serum, for example, a sample may refer either to a single "aliquot" of serum or to multiple aliquots obtained from a single tube of blood. A second problem arises from collection protocols. For example, unit costs may be less when blood drawn at one time point is sufficient for multiple tubes rather than just one tube. The type of material also determines the relative costs associated with sub-dividing: serum, for example, is normally aliquoted just once, while a DNA solution may be aliquoted on numerous separate occasions. In our analysis, the sample cost has generally been ascribed to one portion of material collected at one time point for one patient.

In the light of such considerations, this report does not specify the cost per sample at individual biobanks and is unable to suggest a universal cost model for individual or networked biobanks. However, the cases do enable us to identify some of the main variables that affect costs. Table 2 captures the main cost drivers for sample collection and processing. Note that we provide representative examples only and that, in some situations, the designation of "less expensive" or "more costly" may be reversed (e.g. robotic 
processing may prove more expensive than manual processing when there is a low throughput of a sample type).

Table 2 Key cost drivers with representative examples for samples collection, processing and storage

\begin{tabular}{|c|c|c|c|c|}
\hline \multirow[t]{2}{*}{ Process } & \multicolumn{2}{|l|}{ Variables } & \multicolumn{2}{|c|}{ Examples of variables } \\
\hline & Project-specific & $\begin{array}{l}\text { Facility- } \\
\text { specific }\end{array}$ & Less expensive & More costly \\
\hline \multirow[t]{5}{*}{ Collection } & Sample type & & Saliva & Solid tissue \\
\hline & Donor type & & Patient & Control \\
\hline & Location & & Local clinic & Home visit \\
\hline & Time of day & & Morning & Night \\
\hline & Time-point & & Longitudinal & Single \\
\hline \multirow[t]{6}{*}{ Processing } & Processing method & & Aliquot liquid & FFPE section \\
\hline & Final concentration & & Not specified & Normalised \\
\hline & Number of aliquots & & One & Multiple \\
\hline & Size of aliquots & & Microtube & Block of tissue \\
\hline & & $\begin{array}{l}\text { Technical } \\
\text { resource }\end{array}$ & Robotics & Manual \\
\hline & & Quality & Not specified & Externally audited \\
\hline \multirow[t]{8}{*}{ Storage } & Storage conditions & & $\begin{array}{l}\text { Room } \\
\text { temperature }\end{array}$ & Liquid nitrogen \\
\hline & $\begin{array}{l}\text { Ability to replenish and } \\
\text { samples stability }\end{array}$ & & DNA & Fresh tissue \\
\hline & & $\begin{array}{l}\text { Emergency } \\
\text { back-up }\end{array}$ & $\begin{array}{ll}\text { No } & \text { spare } \\
\text { capacity }\end{array}$ & Reserve facilities \\
\hline & & $\begin{array}{l}\text { Consumable } \\
\text { costs }\end{array}$ & Bulk discounts & List price \\
\hline & & Data entry & Single & Double \\
\hline & & Labelling & Hand-written & Integral 2D barcode \\
\hline & & Tracking & Paper records & Customised LIMS \\
\hline & & $\begin{array}{l}\text { Alarms and } \\
\text { environmental } \\
\text { monitoring }\end{array}$ & None & $\begin{array}{l}\text { Remote alarm and auto } \\
\text { temperature logging }\end{array}$ \\
\hline
\end{tabular}

Some biobanks had well defined costs. UK Biobank, for example, was established with a clear remit and with a defined budget that covered all aspects of biobank construction, sample collection, storage and processing. Its target demographic was drawn from the normal population and identification was then facilitated through access to NHS records. All the planned 500,000 volunteers were recruited on time because the target population was a sufficiently large (9 million people were invited to volunteer [43]) and because there was public altruism, effective publicity and a perception of the "common good". 
Although it might be expected that a project to collect samples from the general population outside of existing infrastructure would be expensive, in fact costs per sample were relatively low. This reflected scale economies. The large scale of the project justified a substantial investment in equipment (e.g. robotics); in efficient accrual (via high-throughput collection centers); and in efficient use of labor (short contracts at an appropriate level of expertise).

By comparison to UK Biobank, most biobanks have a less precise cost model and may even be unable to analyze specific costs retrospectively. However, there was evidence that there is a shift towards trying to elucidate "real" costs in the future. This may be due to increased financial instability and the consequent need for accountability. In particular, Nottingham Health Sciences Biobank (NHSB) has invested significant resources in identifying its costs and developing a business plan. NHSB and other biobanks located in hospitals/university hospitals are likely to play increasingly important roles in translational and clinical research, as in the US [40]. NHSB is actively planning to recoup the full cost of biobanking (including the institutional and infrastructure costs) primarily through the provision of samples to commercial users.

The extensive analysis undertaken by NHSB for the preparation of its business strategy has highlighted some of the key costs associated with biobanking. For example, NHSB has indicated that, when taking into account all of the costs associated with the preparation of a fresh frozen tissue, only about $12 \%$ of the total is directly associated with the collection, processing and storage of a sample, a similar proportion is attributable to data collection, but almost half of the overall cost is attributable to overheads for the biobank, for pathology services, for administration and for the hospital trust as a whole. The figures for NHSB may be representative of similar biobank models elsewhere. NHSB has employed some interesting processes to reduce costs and increase the efficiency of accrual and processing (e.g. it uses existing donors to seek consent from potential donors and it seeks generic consent to increase opportunities for future research).

NHSB also has committed funding to develop Information Communication Technologies (ICT) 
infrastructure (see below), highlighting the importance given to searchable samples with well managed data. All the case study interviews revealed that well-managed, full data contributes significantly to the research value of samples. Indeed, if $R \& D$ is based on inadequate data management, then fewer experimental conclusions will be robust and this will have significant cost implications in the mediumlong term, including, possibly, poor commercial decisions. Of course, provision of poor quality samples and annotations creates reputational risk for the biobank and its owner. Like NHSB, some cases were investing significantly in collating data (manually or automatically) into a comprehensive and searchable database, while others preferred a simpler system, possibly dependent on future manual access to clinical records or via a currently unspecified electronic mechanism. In all cases, it was clear that there were significant resource implications either in the short term (creation of a "system") or in the long term (in retrieving the relevant information). Where a database already exists, perhaps for an associated study (e.g. with the Abcodia serum collection, or the AZ clinical trials data) or through retrieval from an electronic NHS database, there is an obvious cost saving to be made, assuming good quality and management of the information.

The construction of biobanks can incur large costs. This is exemplified by the high specification, purposebuilt facilities established across two sites by UK Biobank at a cost of well over $£ 10 \mathrm{~m}-\$ 15 \mathrm{~m}$. Although UK Biobank had particularly advanced systems for robotics, cold storage, security, and fire suppression, it nonetheless indicates the scale of potential costs. In contrast, other establishments may have incurred costs progressively (for example in converted facilities) or over a longer period of time. These costs will be "hidden" within wider financial support, as was frequently seen in many of the cases studied here. Sometimes, even the purchase of associated equipment may be linked to previous budgets or institutional facilities (as seen in the small collection case). It is important to recognize that these "hidden" costs do not disappear just because they are not seen - even when they represent a reuse of otherwise underutilized facilities or resources. Although creation of planned facilities represents a large investment, it has historically been paid for by public funders as part of research project support. 
This has led to facilities that are funded for a three to five year period but not thereafter, so that biobanks must search creatively for new funding streams to continue their operations and address depreciation. In the case of the CIGMR Biobank, this discontinuity caused an exacerbation of problems when a new financial model was unfamiliar and not supported by the institution's finance system. Discontinuity of funding not only risks wasting the original investment, but also puts at risk the scientific value of the collections. It should be noted that donors are not usually advised of such risk. We also note that funding by disease area can result in duplicated or under-utilized resources.

Running costs were diverse and highly variable, but salaries represent a very large outgoing for all biobanking models. The figures are difficult to untangle. Even UK Biobank, with its relatively transparent model, had highly variable salary expenditures depending on the stage of recruitment. Its collection teams were frequently recruited on fixed term contracts and worked in different geographical areas. By contrast, NHSB utilized staff that work in a flexible manner within a broader job remit. This increases efficiency, but relies on effective time management and underlying facility support that permits continuous effective use of staff when no samples need processing. The CIGMR Biobank also utilized a flexible staffing model with skills often deployed across both the biobanking and non-biobanking aspects of the overarching organization (CIGMR). For example, its quality management system encompassed administrative, managerial and some R\&D processes. There was also role flexibility to handle peaks and troughs of sample throughput. Over half the running costs for CIGMR Biobank relate to salaries. The second biggest expenditure was maintenance and depreciation. This probably reflects the specialized research area (genetic and other biomarkers) and the use of robotic liquid handling that is considered critical to consistent sample quality. To illustrate the diversity across our cases but the common dominance of salaries as a cost, we note that $\mathrm{AZ}$ has a core team on two main sites assigned to biobanking. The team's annual salary costs are just under $£ 1 \mathrm{~m}-\$ 1.5 \mathrm{~m}$ while the biobank's calculated annual capital resource is $\sim £ 50 \mathrm{k}-\$ 75 \mathrm{k}$ and the annual spending for consumables is less than $£ 20 \mathrm{k}$ $\$ 30 \mathrm{~K}$. 
This may reflect a high level of "hidden" financial support from within the company, together with factors such as individual research teams incurring separate collection costs when samples are obtained from external sources and factors arising from out-sourcing of some services (e.g. DNA processing).

Aside from salaries and equipment maintenance (including IT/LIMS), other on-going annual costs associated with biobanking are relatively low. These costs include consumable supplies, licensing and administration (for example to ensure regulatory compliance), energy, training, marketing, transport and courier costs. However, these costs are also highly variable; for example, UK Biobank spent a significant sum on sample transport as it operated a model with a central storage facility and outlying satellite recruitment sites.

In addition to our cost analysis for individual biobanks, the UK Brain Bank Network was interrogated as a model for enhanced networking. This network was supported by the main grant funder in this area (Medical Research Council, MRC) to promote brain research. Recognizing the difficulties in collecting brains, the aim was to introduce a more coordinated strategy for collection and access. At the individual brain biobank level, cost savings and benefits are realized through, for example, the use of a centralized database to enable wider access to samples. This, in turn, provides an improved justification for future funding as network members can demonstrate increased outputs based on collaboration and less duplication. This coordination benefits the funders (public and charitable) by reducing overlapping funding requests. Furthermore, the network has also enabled the biobanks to have an enhanced "voice" that can make the case for funding of priority areas in resource development and in experimental work. Creation of centralized administrative and IT resources can clearly provide a cost saving for relatively small biobanks, each of which has limited resources.

The Small Collection demonstrates that enthusiastic individual researchers or clinicians targeting specific patient groups can collect samples with very little additional resource by using existing systems that provide access to patients (usually via the NHS). However, these individual researchers have few resources available to process, store or distribute samples. If these capabilities were made accessible to 
them and, importantly, human resources policies and practices rewarded these activities, then samples from individual researchers and clinicians could be managed relatively cost effectively.

In summary, our data on costs indicated a diversity of models and enabled the identification of the main cost drivers. Carefully planned, large-scale collections can recruit in a relatively efficient manner. However, short-term funding risks under-utilization of resources and equipment. Similar scenarios exist across other grant and publicly funded resources, whereby a lack of guaranteed maintenance funding leads to insecurity and, ultimately, the potential failure of initially expensive resources. It is important to move away from the dominant short term biobank funding model that links the biobank to the lifetime of the individual research project. Instead, a model is required that can ensure long-term utilization of a biobank's resources. This implies long-term core funding of appropriately staffed facilities where standards and equipment are maintained and improved and where depreciation is allowed for.

\section{Information communication technologies (ICT)}

Investment in ICT is appropriate for all biobanking processes starting from the recruitment of subjects through to publication of research results, and biobanks seek to allocate funds to ICT (e.g. the NHSB: $£ 1.2 \mathrm{~m}$; CIGMR Biobank: £65k p.a.; UKBBN: 1 full time employee). Key investment priorities are sample tracking and an access portal for internal and external users. An emerging priority is the creation of links to clinical and experimental databases using common standards. These permit the full annotation of the samples, if there is appropriate standardization of ontologies. This standardization of, for example, disease coding and samples classification is ongoing and resource consuming. If standardization is delayed then this becomes a critical bottleneck in biobanking.

Interoperability between biobanks is an increasingly important scientific issue. Indeed, international interoperability is desirable because of the global nature of R\&D. UKBBN reported that it is building on existing European systems to enable sample sharing and to avoid the high costs associated with customdesigned ICT solutions. 
From a political perspective, there are clear signals [44] that ICT development should build on existing complementary infrastructures (e.g. e-infrastructure and bioinformatics facilities). Opportunities exist to construct a biobanking infrastructure interfacing with a biomedical informatics infrastructure arising from the European bioinformatics DRIS called ELIXIR which is coordinated from Cambridge UK [45]. The Department of Health's investment in health data sets is also particularly relevant. Such interfaces would provide a national scientific advantage and also act as an incentive for research to be located in the UK.

\section{Financing}

In our case studies, biobanking was financed from a variety of sources, reflecting their location and function. However, with the exception of AZ biobank, they have predominantly been supported by mixed public funding. Our data is consistent with findings in a US survey, where $78 \%$ of biobanks were funded by the federal government, the larger host organization (presumably including universities and hospitals), individuals, federations or the state government [8].

Public funding of research (including biobanking) is widely recognized by both politicians and economists as critical because:

- Knowledge (the output of research) shares properties of a public good [46].

- The generation of knowledge stimulates the generation of new knowledge.

- The benefits of research are widespread, diffuse and unpredictable.

- Limited access to knowledge can significantly slow the pace of innovation.

- Research can also be a long way from market (the commercialization process from invention to a new product entering the market takes on average 15 years). This then acts as a disincentive for firms to invest extensively in $R \& D$ unless it is clearly product-related, except to maintain capabilities in the field.

Additionally, economists recognize that public subsidies are justified in situations of market failure, i.e. 
when the market is not allocating resources efficiently [47]. Market failure is expressed in biobanking (globally) as a lack of coordination between biobanks and poor visibility of samples, 
combining to impede access to sufficient numbers of high quality samples necessary to underpin Research Development and Innovation (RDI). Biobanking today is inefficient and is negatively impacting the delivery of stratified medicine and resulting in a loss of societal and economic benefits. Combined with evidence [48] that public spending on RDI stimulates the private sector to invest, there is a strong rationale for collective action that has the aim of promoting knowledge generation and sharing.

This rationale has been expressed in widely accepted form by Stiglitz [49]:

"The central public policy implication of public goods is that the state must play some role in the provision of such goods; otherwise they will be undersupplied. If firms cannot appropriate the returns to producing knowledge, then they will have limited incentive to produce it: in deciding how much to invest, they will look only at the return that they acquire, not the benefits that accrue to others."

It is highly unlikely that a national biobanking solution can be financed entirely by commercial funds. Even if individual firms were required only to make a contribution, it would be difficult to design and coordinate comprehensive and fair contributions across all potential industrial beneficiaries sustainably. The difficulty arises from issues such as free-riding, the exclusion of organizations (including small and medium enterprises) and excessive transaction and management costs. These are issues that are likely, first, to impact on the perception of equity which is fundamental to the sharing of samples, and, second, to impact on the ability of researchers to access those samples. This could have a negative impact on innovation.

However, industrial users of a national biobanking solution could make a fair contribution to any centrally funded scheme. Currently there is no national financial oversight or guidance associated with the provision of samples to industry, and supply tends to be negotiated on an ad hoc basis or governed by the philosophy of each individual biobank. Although there was a general consensus among the publicly funded biobanking community that samples should not be "sold for profit," a number of biobanks adopted 
a tiered fee structure, generally led by the ability and willingness to pay rather than reflecting true costs (the price is not set by the market). Tiered fee structures are generally presented as "access fees" (i.e. the fee is paid for access and happens to be charged at the point of exchange). The structures are employed to enable a degree of cost recovery and to subsidize academic users. There were no examples in the cases of membership fees, though this may be an option for a national solution. Other possible options include companies contributing to the funding pot and fees for service in the context of public-private research partnerships.

Construction of each of the biobanks in the cases involved some form of "strategic" investment, unless, as for example in the Small Collection, the biobank evolved from smaller scale collections into larger or more formalized facilities (this has frequently been driven by regulatory requirements). All the biobanks we studied have been dependent, as elsewhere $[8,50]$, on either core or project funding and, in the case of corporate biobanks, are usually financed by the global budget of the institution. For example, the NHSB invested in the development of a business plan aiming to recover costs of running the biobank (this included the hospital trust's overheads, but not the access committee or a return on the initial investment from the hospital's R\&D budget). The business plan projected that the biobank could cover its own costs by March 2014, including pathology and overheads by March 2015, and the Trust's overheads by March 2016. These projections involved a significant shift in financing streams and activities including the assumption that non-grant income would double each year. Over $£ 3 m$ of $R \& D$ funding is ring-fenced for the NHSB until March 2015.

Sustainability may only be achievable through a form of open data mandate [39] where principal investigators collecting samples for their research are obliged by project funders to use a recognized biobank for samples and data management and where the funders pay the biobank directly for that management. This resolves a conflict of interest between the PI and the biobank (the PI is conflicted between winning support to address a research question and winning support for research infrastructure) and allows for maintenance, depreciation and endogenous development of the infrastructure. 
Related to this, a critical juncture in the life of a biobank is the transition from funding for construction to funding for maintenance and development of collections (including the related tools, technologies and techniques). The case studies showed that the maintenance of a biobank within a public institution was often largely dependent on research project income, where a proportion of income from projects was allocated to biobanking. This way of maintaining a biobank has its problems. While there may be some support for the implementation of processes new to the biobank, this support is irregular and may be intermittent. Many biobanks were in receipt of funding from multiple sources, thus increasing the administrative burden of running the biobank, and resulting in the widespread cross-subsidizing of biobank activities. Some of this cross-subsidizing is transparent, but much of it is not. This, then, creates a variety of problems including a lack of information about real costs; distortion of the market; low morale among biobank staff; raised staff turnover; and job insecurity, particularly in the university sector. Innovation in biobanking methods is also affected negatively, owing to less "slack" in the system for laboratory and management methods research or innovation.

Any discussion about financing arrangements cannot ignore the current political or economic environment. Support for research capital in the UK has experienced significant fluctuations in the past five years. Economic austerity following the financial crisis led to 53\% capital cuts in 2010/11, but since then a series of initiatives has raised investment in infrastructure culminating in a government commitment in December 2014 to increase capital investment in real terms to $£ 1.1 \mathrm{bn}$ - \$1.6bn in 2015-16 and then to grow this in line with inflation each year to 2020-21. Following an open consultation, a Capital Roadmap [51] indicates priorities for investment including investment in biobanking via partnership funding for charities investing in collections of biological material and linked data for research purposes. The Research Councils UK (RCUK) Strategic Framework for Capital Investment [52] informs the "identification, prioritization and timely realization of key capital investments" and is organized around seven "major research challenges and opportunities where the UK either has an international lead in research, or is poised to take this position." 
A national biobanking solution supports research in three out of seven of these key areas: Health, disease and aging; Population change and diversity; and synthetic biology. A strong argument may therefore be made for public funding in this area. However, in the context of government that favors reducing its role [53], the creation of a coordinated biobanking network may be dependent in part on resource commitment by industry and charities.

A coordinated approach across the public and private sectors will be critical to ensuring a successful design that meets the needs of stakeholders, as well as incorporating funding from a variety of sources in an equitable way. However, our research suggests that investments should be strategic and long term in order to sustain a coordinated national biobanking solution.

\section{Access Fees}

Access fees provided an additional source of finance for some of the cases, although this was highly variable. NHSB reported that an extensively annotated sample may be worth twice one that has limited data. Although price variation can be expected according to the type of samples requested, the accompanying data and any extra service provision, these factors do not fully explain the variation. Some additional reasons have been identified. However, while many biobanks reported flexible financial arrangements, details about calculation methods were not usually provided. Some biobanks used flat rates (usually for data, sometimes for samples). None could provide an average unit price for a sample. Stipulations made by the funder are also an influence on a biobank's pricing model.

The common use of tiered fee structures, based on the type of researcher, rather than the type of samples, complicates matters further. For example, NHSB charged local researchers the "direct cost plus Pathology overheads" (reflecting rates achievable from funding grants, because main funding bodies cover direct costs only, i.e. $33-55 \%$ of full cost recovery). Some local researchers were given access to samples "free of charge" for pilot work relating to research proposals. In a tiered fee model aiming to recover full costs, industrial partners may be required to pay above cost in order to supplement local and academic research. 
However, there are no examples among the cases, or found in the literature [54], where full cost recovery is achievable. A two tiered fee policy, where industry users are charged commercial rates, is applied to asset collaboration [55]. However, one interviewee from a case study where fees are tiered reported feeling that industry users may be given priority of access, suggesting that tiered fees can cause tension for industry users and for public organization users.

There are significant differences in how price is calculated. Some biobanks calculate the price to cover supply costs (not including samples, accrual, storage or infrastructure), some calculate price to cover direct costs only and some calculate to cover both direct and indirect costs (though on closer examination even those aiming to recover only direct costs have different criteria). Interviewees reported that price often reflects the users' ability or willingness to pay, just as much as costs. Often this means that price levels are not set by the market and are below cost. Profit generation may be possible in exceptional circumstances, but there is limited evidence for this in the cases we examined. Indeed, even commercial biobanks may operate at low margins and hence are vulnerable. This is consistent with market failure theories and thus supports the case for subsidy of biobanking with public and private funds to ensure its economic and health benefits.

\section{Access}

All of the biobank cases provided some visibility for and access to samples under conditions which, to some degree, were restrictive. This is termed "controlled access." Restrictions arise from ethical, regulatory, legal or cultural considerations. Some arise from the business model. The dominant and most consistent restriction was the use of a committee to prioritize access and to seek to ensure the best possible use of samples. Ensuring that samples are used in scientifically and/or commercially valuable research contributes to the innovation potential of samples and the overall benefit they deliver. Once access committees are accounted for, some biobanks exhibit variable degrees of openness of access.

For example, AZ biobank was more "closed" than open; while Abcodia was more open than closed (assuming users are able to overcome the barrier of cost). The cases owned by universities, hospitals and charities can be characterized as more open. 
Overall, the level of access tends to reflect the owner (or host), the function of the biobank and funding streams. We found that publicly funded biobanks were more likely to support wider/external access, although internal or collaborating researchers tended to be prioritized. The corporate AZ biobank was only accessible to internal researchers and contracting organizations, although AZ supported the proposition of a national biobanking solution. The commercial biobank could participate in a crossaccess arrangement given the ability to charge an access/service price inclusive of profit. A national biobanking solution would not preclude a role for intermediaries that source samples to order.

In all of the case studies, access to samples was conditional upon mutual benefits (either some form of research collaboration and/or a financial transaction). This finding is very similar to a study on asset collaboration [54]: it is clear that whatever access mechanisms are used they should be widely perceived as equitable and they should be inclusive rather than exclusive. The importance of perceived equity is also important in relation to the distribution of benefits arising from the use of samples. Conflicting opinions were expressed by interviewees on the ownership of outputs (including new knowledge, publications and products). Some interviewees argued that samples are critical to the production of new knowledge and biobank scientists should be included as authors on resulting publications. Others sought no authorial recognition. None expressed the opinion that intellectual property (IP) rights should be granted to the biobank. A variety of arrangements were seen across the cases. For example, UK Biobank and UKBBN did not conduct research, so benefits to the biobank arose wholly from the enrichment of sample annotations. Both organizations perceived their value to lie in supporting research undertaken by others. NHSB asks its users to contribute to the enrichment of samples and requires published or patented data to be shared with the biobank as raw phenotypic data that can be associated with a sample. NHSB requires acknowledgement in publications but does not require a stake in any IP or authorship. The beginnings of a consensus may emerge based on the notion that the equitable distribution of benefits comprises enrichment of sample annotations by users and their acknowledgement of the biobank in their publications [56]. 
Access to a sample by third parties is impossible if they are not aware where it is and what kind of data describes it. The sample needs to be visible. This issue is a concern for industrial and academic researchers alike. Many biobanks, especially smaller ones, have limited strategies or resources to enable visibility. However, attention has been paid to this issue by projects such as UK Biobank, UKBBN and the CIGMR Biobank. Ensuring the ready visibility of samples, their annotations and their location is a critical task for a national biobanking solution. Work has been initiated on visibility at the national level in the UK and US and across borders in the EU [57]

\section{A national biobanking DRIS: considerations}

The existing fragmentation of biobanks and the resulting lack of transparency incur high search costs for users, duplication of funding, underutilization of existing samples and limited opportunities for strategic planning (e.g. prioritizing accrual of specific tissue types or disease areas; conducting multi-partner research projects). Fragmentation also undermines confidence in consistency of samples and impedes the sharing of best practices, including quality standards. Gaps in the financing of the maintenance of collections and data associated with samples can result in the loss of valuable resources and unnecessary duplication, for example, of equipment, aspects of management and even of sample types within specific disease areas. Financial gaps also reduce cost transparency as biobanks create opportunities for crosssubsidies. This then suggests a need for a national biobanking solution.

Such a solution might be either a single central national biobank or a national biobanking DRIS. A single facility is neither desirable (from an access, cost or innovation perspective) nor viable (operationalizing it would be extremely difficult if not impossible). The most efficient and effective way of developing a sustainable national biobanking DRIS that permits all biobanks to participate is through coordinating existing and emerging biobanks and biobank networks.

Benefits associated with a national biobanking DRIS can be understood in general terms as "network effects." These effects include increased transparency, information sharing, efficiency, consistency and quality as well as reduced duplication and transaction costs. Critical mass (i.e. the number of biobanks in 
the network) is required to realize the benefits associated with networking, as is standardization that enables interoperability.

There are also potential general socio-economic benefits. They include the creation of: new scientific knowledge; new science, technology and innovation opportunities; new technologies and instruments; spin-off firms and new industries; and jobs. Other benefits include: supporting existing industry; contributing to training and development; attracting research funds; attracting industry funding; improving management capacity; boosting local expenditure and raising tax income.

A strategic approach to a national biobanking DRIS requires [1] coordination among policy makers and the main research funders (with a public funder taking the lead) [2] a reconfiguration at the organizational level in the longer term, for example, designating biobanking as a research activity in research funders' agendas and [3] coordination at an operational level in respect of standards and governance.

It is clear that the opportunity costs of not taking a strategic approach to biobanking are high, and could include the decline in the global position of a nation in biomedical research and a loss of its attractiveness to industries that commercialize this knowledge and deliver it to citizens.

Although the impact of individual biobanks on research has been well documented, it is difficult to isolate the effects of a national biobanking DRIS before it has actually been created [18, 19, 47]. Measuring returns (e.g. benefits) is difficult as they are wide-ranging, often indirect and unpredictable and they take time to be realized. However, we can identify the nature of these returns:

- Increased visibility and access to samples. Access to large numbers of quality samples and associated data would help to ensure adequate statistical power in research studies (and performance assessment). This has the potential to speed the development of stratified medicine, accelerate the research cycle and strengthen meta-analysis. Access via a single web portal would enable better planning of future sample acquisition.

- Increased value of samples through the adoption of standards that ensure consistency and improve quality. A DRIS should also increase the value of existing samples by their enrichment with more 
data and with new data.

- Reduced costs to the user (e.g. search costs across multiple biobanks), to the biobank (e.g. reducing speculative approaches and marketing costs) and to funders (e.g. maximizing the potential of existing collections).

- As new data becomes associated with remaining portions of samples, coordination can then also support the creation of wider ("spill over") benefits, including access to knowledge, that extend beyond a single organization. New knowledge is then diffused quickly and innovation is supported for a variety of organizations $[58,59,60]$. This is one mechanism through which RIS plays an increasingly important role in knowledge creation and innovation and has a positive effect on economic and social welfare $[61,62,63]$.

- Coordination will enhance cost transparency and confer cost-effectiveness through "network efficiencies" (e.g. individual biobanks delegate some aspects of policy and its implementation to the coordinating body).

We can also identify significant challenges involved in constructing a national biobanking DRIS:

- For an RIS to operate most effectively, many biobanks or project-based networks need to participate.

This can be achieved over time by encouraging participation and highlighting the benefits.

- The benefits of participating should, of course, be greater than the costs. Encouraging participation requires careful consideration of issues including trust (e.g. trust that samples will be used in the best possible way); competition in science; competition across organizational types; intellectual property rights (except in pre-competitive collaborations).

- Academics are often penalized for undertaking managerial and administrative tasks such as those required for RIS development. Such tasks are considered to interrupt research and reduce outputs. The academic system is structured to reward individual research effort (e.g. the Higher Education Funding Council for England, rewards individual over team outputs). Although reward systems in industry are orientated toward organizational/project goals, similar issues exist there too. Hence, guidelines on study co-design, publication practices and intellectual property rights need to 
- be clearly defined from the start for a biobanking DRIS.

- Recent research on asset collaboration [54] found that sharing of facilities was contingent on reciprocity and perceptions of equity. Sharing was most likely to occur for "neutral assets" (equipment acquired for collective use). Anecdotal evidence in the biobank and research community suggests that there can be reluctance among individual collectors to share samples. However, a biobanking DRIS constructed as a shared facility with neutral assets would help to overcome some of these issues.

- Researchers wishing to participate in a national biobanking DRIS face new or increased costs and there are likely to be intra-institutional barriers to meeting those costs. These costs include: dedicated staff to interface with upstream and downstream users; management of information systems and their interfaces (including systems concerned with samples history); ensuring appropriate training of biobank personnel; ensuring compliance with current consent and access governance policy; developing, implementing and assuring consensus standards with other biobanks. The intrainstitutional barriers can be avoided via an overarching funding strategy entailing a form of coordinated (or aligned) continual funding. It is important that the construction of a DRIS maintains the diversity and independence of biobanks while enabling coordination across biobanks.

\section{Recommendations}

The work described here started with the aim of developing a "cost model" for a national solution to the lack of sufficient numbers of high quality samples for the development and adoption of stratified medicine. The case studies identified the main cost drivers in biobanking; the existing financial arrangements that are contributing to the current situation of market and system failure; and opportunities to overcome these failures. An overview of problems experienced in the US due to fragmented and uncoordinated biobanking has been published [8].

It is clear that there are significant benefits associated with promoting national coordination between 
biobanks and we have outlined a strong rationale for public funding of core activities, potentially with additional financing through membership fees and/or marginal access fees. This was first proposed [10] two decades ago by the OECD: "governments must be encouraged to provide a baseline of long-term, core funding" to all types of biobank. This requirement has again been emphasized in 2010 with respect to RIS across biology programs in the US [35].

\section{Financial arrangements}

Identifying an optimum way of financing a national biobanking DRIS is informed by, first, the viability of revenue models and, second, the viability (and desirability) of different operating models. Transaction 
costs [64] have an impact here. Managing a diverse range of biobanks and financial streams takes time, management and accounting skills - activities with associated costs that need to be factored in. Also, sustainability is critical and, hence, unpredictable revenue streams make long-term planning, expansion, and improvement of infrastructure a challenge.

A critical requirement for biobanks is that they should have the capacity to preserve content and services for an extended period so as to increase their value to the user community over time. However, biobanks require not only longevity but, because they are dynamic infrastructures evolving over time, there are also costs associated with renewing and maintaining the data associated with samples and with developing and improving biobanking laboratory and management methods. Biobanks and biobanking are often funded from discrete investigator-led projects in the UK. Funds therefore tend to be time restricted and this has profound implications for longevity and innovation. Furthermore, in the US, it has been noted [35] that funders supporting research in biology prefer to support what they consider novel and biobanking does not directly satisfy this requirement. Financial discontinuities inhibit biobank longevity, innovation and strategic oversight.

There are benefits associated with biobanking being located within a policy framework specifying a broad strategy for addressing disease or for addressing an unmet public need. However, there are also benefits of biobanking being project-oriented and thus developing from the "bottom up." A scheme for this has been proposed by STRATUM in its Exploitation Plan [65].

Coordination requires dedicated resources, including funding for strategic management duties, e.g. "buying" the time of representatives from stakeholder organizations; a permanent operational staff, e.g. director; IT manager; coordinators for quality systems; network development; training; ethics, legal and societal issues; a coordination center (with appropriate facilities and IT equipment); and necessary activities (e.g. travel and subsistence, communication). Co-ordination should be financed centrally by public funds, possibly a research council in the first instance but with a view to transition to the NHS as 
biobanking becomes recognized as essential to improving health. Potentially, this funding could be supplemented with industrial sponsorship through a mechanism such as a tiered RIS membership fee or contributions to the central funding stream. The details of such a structure would have to be carefully considered so as not to discriminate against potential users, particularly SMEs with fewer capital resources.

Simultaneously, the financial arrangements for existing individual biobanks should be reconfigured. Beyond the initial construction stage (the most expensive stage where, paradoxically, most funding has tended to be available) biobanks struggle to finance their operations [53]. Based on our findings, we recommend:

- Acquisition of samples. Acquisition can be organized in different ways, however, it is frequently project-oriented. The financing of both sample accrual and storage (for defined periods) should be included as costs in project proposals. The category of such costs (consumables, estates or service support) is a matter that requires attention.

- Facilities. This refers to equipment, its management, maintenance, depreciation and replacement, rent and utilities. Facilities require ongoing funding that can be separated from project-specific funds. Many biobanks are supported by institutional funds to some degree. This arrangement could be extended so that central public funds are distributed to host institutions in the public sector through the research councils and other routes (including the NHS) and then allocated to the facility.

- Access/distribution of samples. There are marginal costs associated with distribution and these costs could be paid directly by the (secondary) user [a] from project funding for publicly-financed R\&D [b] from project funding for public-private $R \& D$ partnerships [c] via an access fee for privately-financed R\&D. These access fees could be tiered so that industrial users subsidize academic/not-for-profit users.

- "Controlled access" with open access features supports the "best possible use" of samples and associated data. The majority of biobanks in the case studies manage access through a committee or 
other mechanism designed to assess the scientific merit of project proposals. This arrangement reflects best practice and can support knowledge sharing while conserving valuable finite material. Open-access (with usual anonymity practices) for associated data (and software) has the most beneficial impact on knowledge creation and innovation, and should be pursued. In order for the DRIS to operate as a dynamic and sustainable resource (i.e. increase in value over time) it is highly desirable that samples be continually enriched with high quality annotations (both clinical and experimental). This data enrichment requires, for example, that users submit new knowledge created from the use of samples (after publication) to the biobank or associated data controller. It also requires that the biobank be able to link the samples to external data sources such as the donor health record (or a version of it). The biobank or data controller should perform the data enrichment process for data types that follow national standards. This will increase compliance by reducing the time and effort costs to the users, as well as maintaining format/ontological consistency and quality. Data enrichment could be mandated by funders.

The scientific value of samples is optimized when samples and data are consistent across the network and when policies are aligned. The emergence of a national biobanking DRIS should build on previous work (e.g. the Human Tissue Authority codes of practice [66]) and enrollment in the DRIS should be dependent on the adoption of a core set of policies and standards [16]. Individual biobanks will benefit directly through the diffusion of best practice, and access to standardized policies that meet (or exceed) regulatory requirements. This will benefit users by increasing the quality and consistency of samples. The implementation of a national biobank accreditation system would support standardization and reassure the wide range of stakeholders in biobanking. This has cost implications (license fees and inspections).

This report has examined the "as is" situation for a variety of biobank types. Recommendations to overcome the current situation of market and system failure have been based on primary and secondary data. However, as data on the costs and benefits of biobanking are limited, and the analysis based on small number of cases, this research has been exploratory and the findings will benefit from validation 
and extension internationally. Biobanks reporting recently on their finances $[67,68,69,70,71,72,73$, 74] provide a starting point for such work.

\section{Acknowledgements}

We acknowledge support for this study from the Technology Strategy Board (renamed Innovate UK [75]) with matching funds from AstraZeneca and GlaxoSmithKline. The study was a work package in STRATUM (Strategic Tissue Repository Alliances Through Unified Methods), a project to specify a national solution for the collection of human biological samples and for ensuring their accessibility. STRATUM addresses a topic in the Stratified Medicines Program [76] to develop business models for capturing value created in the stratified medicine value chain. STRATUM partners were: AstraZeneca, GlaxoSmithKline, Lab21 (a clinical diagnostic company) and the universities of Manchester, Nottingham and Leicester. Its aims were endorsed by the Royal College of Pathologists and the Experimental Medicine Funders Group which draws together UK public research funders, industry groupings and 136 medical research charities.

We thank the following for their insights and perspectives: Margaret Clotworthy (Human Focused Testing), Chris Womack, Rachel Mager and Mark Robertson (AZ), Balwir Matharoo-Ball and Brian Thomson (NHSB), James Ironside and Chris Tindal (UK Brain Bank Network), Lesley Stubbins (GSK), Caroline Magee (NCRI), Aino Telaranta-Keerie (Lab21), Louise Jones (CRUK), Catherine Elliot and Joanna Jenkinson (MRC), Ariane Herrick (Salford Royal NHS Foundation Trust), Paul Downey and Pamela Moore (UK Biobank), David Walsh (ARUK Pain Center), Gisli Jenkins (University of Nottingham), Finbarr Cotter (Royal College of Pathologists), Julie Barnes and Ian Jacobs (Abcodia), Kate Dixon, Bill Ollier, Melanie Lythgo and Craig Sykes (University of Manchester). 


\section{Conflicts of interest}

The case study "CIGMR Biobank" is led by MY and "Small research collection" is managed by RO.

\section{References and notes}

1 Watson PH Barnes RO. A Proposed Schema for Classifying Human Research Biobanks. Biopreservation and Biobanking. 2011;9:327-333.

2 Davis JC, Furstenthal L, Amar AD, Norris T, Sutaria S, Fleming E, Ma P. The microeconomics of personalized medicine; today's challenge and tomorrows promise. Nature Reviews, Drug Discovery. 2009;8:279-286.

3 Poste, G. Bring on the Biomarkers. Nature 2011;469:156-157.

4 A well annotated sample is one where the associated data is accurate and standardized and encompasses full information about the sample, the subject and the environment. A high quality sample is one that has been processed consistently in the same way as other samples to which it may be compared, where it is annotated with information about the processes used and any process improvements that have been made and where a quantitative or semi-quantitative measure indicates that it is fit for proposed analytic purposes.

5 Department of Business, Innovation and Skills. Office for Life Sciences. Strategy for UK Life Sciences. 2011. www.gov.uk/government/uploads/system/uploads/attachment_data/file/32457/11-1429-strategyfor-uk-life-sciences.pdf. Accessed 13 August 2015

6 Stratified Medicine in the UK: Vision and Roadmap. October 2011. Technology Strategy Board. https://connect.innovateuk.org/documents/2843120/3724280/Stratified+Medicines+Roadmap.pdf/ Accessed 13 August 2015. 
7 RCUK Large Facilities Roadmap. 2010. p.44. RCUK. www.rcuk.ac.uk/RCUKprod/assets/documents/research/RCUKLargeFacilitiesRoadmap2010.pdf Accessed 13 August 2015.

8 Henderson, G.E., Cadigan, R.J., Edwards, T.P., Conlon, I., Nelson, A. G., Evans, J.P. Davis, A.M., Zimmer, C., and Weiner, B.J. (2013) Characterizing biobank organizations in the U.S.: results from a national survey, Genome Medicine, vol 5 (3).

9 Meijer I, Molas-Gallart J, Mattsson P. Networked research infrastructures and their governance: The case of biobanking. Science and Public Policy. 2012;39: 491-499. doi: 10.1093/scipol/scs033

10 OECD Biological Resource Centers: Underpinning the future of life sciences and biotechnology. Paris. March 2001. ISBN 92-64-18690-5. www.oecd.org/sti/biotech/2487422.pdf

11 ESFRI. European Roadmap for Research Infrastructures. 2006. http://ec.europa.eu/research/infrastructures/pdf/esfri/esfri_roadmap/roadmap_2006/esfri_roadmap_2006_ en.pdf\#view $=$ fit $\&$ pagemode $=$ none

12 Networks of RIs: thematic booklets. http://ec.europa.eu/research/infrastructures/index_en.cfm?pg=ri_projects_fp7 Accessed 13 August 2015.

13 European Strategy Forum on Research Infrastructures Roadmap. http://ec.europa.eu/research/infrastructures/index en.cfm?pg=esfri-roadmap Accessed 13 August 2015.

14 OECD. International Distributed Research Infrastructures: Issues and Options. OECD 2014 Paris. www.oecd.org/sti/sci-tech/international-distributed-research-infrastructures.pdf Accessed 13 August 2015.

15 European $\quad$ Strategy $\quad$ Forum $\quad$ Research Infrastructures. http://ec.europa.eu/research/infrastructures/index en.cfm?pg=esfri Accessed 13 August 2015.

16 Biobanking and BioMolecular Resources Research Infrastructure - European Research Infrastructure 
Consortium. http://www.bbmri.eu Accessed 13 August 2015.

17 Human Tissue Authority: find an establishment. https://www.hta.gov.uk/establishments Accessed 13 August 2015 .

18 BETA, CNRS and Universite de Strasbourg. Health and Economic Impact of BBMRI; Evaluation methodology and access rule so biobank networks. Final report - Deliverable D5. May 2010.

19 Technopolis. BBMRI: an evaluation strategy for socio-economic impact assessment. A report for BBMRI WP1/WP7. Technopolis. 21 September2010.

20 Gibbons SMC. Regulating biobanks: A twelve-point typological tool. Medical Law Review. $2009 ; 17: 313-346$.

21 Gottweiss H. Zatloukal K. Biobank Governance: Trends and Perspectives. Pathobiology. 2007;74:206211.

22 Tutton, R. Banking expectations: reflections on the promises of biobanks. Personalised Medicine. 2007;4:436-469.

23 Hardcastle R. Law and the Human Body: Property Rights, Ownership and Control. Hart Publishing. Oxford. 2008. ISBN-10: 1841139777; ISBN-13: 978-1841139777

24 Yuille M, Dixon K, Platt A, Pullum S, Lewis D, Hall A, Ollier W. The UK DNA Banking Network: a “fair access” biobank. Cell Tissue Bank. 2010;11(3):241-251. doi 19672698

25 Stacey G, Hunt CJ. The UK Stem Cell Bank: a UK government-funded, international resource center for stem cell research. Regen. Med. 2006;1:139-142.

26 UKCRC Tissue Directory and Coordination Centre https://www.biobankinguk.org/Accessed 13 August 2015. 
27 van Ommen GJ, Törnwall O, Bréchot C, Dagher G, Galli J, Hveem K, Landegren U, Luchinat C, Metspalu A, Nilsson C, Solesvik OV, Perola M, Litton JE, Zatloukal K. BBMRI-ERIC as a resource for pharmaceutical and life science industries: the development of biobank-based Expert Centers. Eur J Hum Genet. 2014Nov 19. doi: 10.1038/ejhg.2014.235.

28 Reichel J, Lind AS, Hansson MG, Litton JE. ERIC: a new governance tool for biobanking. Eur J Hum Genet. 2014;22:1055-7. doi: 10.1038/ejhg.2014.6.

29 House of Lords Select Committee on Science and Technology, Fourth Report, Human Genetic Databases: Challenges and Opportunities (H.M.S.O., London 2001) www.publications.parliament.uk/pa/ld200001/ldselect/ldsctech/57/5701.htm Accessed 13 August 2015.

30 Evers K, Forsberg J, Hansson M. Commercialization of Biobanks. Biopreservation and Biobanking. 2012;10:45-47.

31 Cambon-Thomsen A, Rial-Sebbag E, Knoppers BM. Trends in ethical and legal frameworks for the use of human biobanks. European Respiratory Journal. 2007;30:373-382.

32 MRC. MRC Ethics Series, Human Tissue and Biological Samples for Use in Research, Operational and Ethical Guidelines. 2001 http://www.mrc.ac.uk/news-events/publications/human-tissue-andbiological-samples-for-use-in-research/ http://www.mrc.ac.uk/news-events/publications/human-tissueand-biological-samples-for-use-in-research/ Accessed 13 August 2015.

33 UCSF. Guide for the Research Use of Human Biological Specimens: Collecting, Banking and Sharing Specimens, $2005 \quad$ (updated 2010). http://www.research.ucsf.edu/chr/guide/UCSFBiospecimenGuideMay05.pdf Accessed 13 August 2015.

34 HUGO Ethics Committee. Statement on human genomic databases. December 2002. www.hugointernational.org/img/genomic_2002.pdf Accessed 13 August 2015. 
35 ESA. Strategies for Sustainability of Biological Infrastructure: Workshop Report, Ecological Society of America workshop, November 2010. http://www.esa.org/esa/wp-content/uploads/2014/02/Strategies$\underline{\text { Sustainability-Biological-Infrastructure-Workshop-Report.pdf Accessed } 13 \text { August } 2015 .}$

36 Royalty stacking arises from the risk that multiple patents may affect a single product.

37 Adhikari R. Patents, royalty stacking and management. World Pharmaceutical Frontiers. 2005;25.

38 A free rider is someone who benefits from resources, goods, benefits, or services without paying for the cost of the benefit

39 Von Hippel E, von Krogh G. Open Source Software and the 'Private-Collective' Innovation Model: Issues for Organization Science. Organization Science. 2003;14:209-223.

40 Henderson GE, Cadigan RJ, Edwards TP, Conlon I, Nelson A G, Evans JP, Davis AM, Zimmer C, Weiner BJ. Characterizing biobank organizations in the U.S.: results from a national survey, Genome Med. 2013;5:3-15. doi: 10.1186/gm407.

41 Tissue Solutions: Provider Of Quality Human Tissue Samples For Research www.tissue-solutions.com Accessed 13 August 2015.

42 Clément B, Yuille M, Zaltoukal K, Wichmann H-E, Anton G, Parodi B, Kozera L, Bréchot C, Hofman P, Dagher G, The EU-US Expert Group on cost recovery in biobanks. Sustainability of public biobanks: a tool for the calculation and recovery of costs. Sci Transl Med. 2014;6:261 fs45.doi: 10.1126/scitranslmed.3010444.

43 Allen N, Sudlow C, Downey P, Peakman T, Danesh J, Elliot P, Gallacher J, Green J, Mathews P, Pell J, Sprosen T, Collins R. UK Biobank: Current status and what it means for epidemiology. Health Policy and Technology. 2012;1:123-126. 
http://www.rcuk.ac.uk/Publications/policy/CapitalInvestment/Accessed 13 August 2015.

45 ELIXIR: a distributed infrastructure for life-science information. https://www.elixir-europe.org Accessed 13 August 2015.

46 A public good is defined by two main properties: non-rivalrous consumption (the consumption by one individual does not stop another individual consuming it) and non-excludability (it is difficult to exclude an individual from consuming the good).

47 Marshall, A. Principles of Economics (8th edition). 2013. Palgrave Macmillan, London. ISBN-10: 0230249299; ISBN-13: 978-0230249295

48 Cohen WM, Nelson RR, Walsh JP. Links and impacts: the influence of public research on industrial R\&D. Management Science, 2002;48:1-23.

49 Stiglitz JE. Knowledge as a Global Public Good in Kaul I, Grunberg I, Stern MA (eds). Global Public Goods: International Cooperation in the 21 st Century. 1999. Oxford University Press, USA. ISBN-10: 0195130529; ISBN-13: 978-0195130522.

50 Department of Business Innovation and Skills. Creating the future: a 2020 vision for science \& research. 2014. https://www.gov.uk/government/uploads/system/uploads/attachment_data/file/383439/141248-science-capital-consultation-response.pdf Accessed 13 August 2015.

51 RCUK Strategic Framework for Capital Investment. Investing for growth: Capital Infrastructure for the $21^{\text {st }} \quad$ Century. RCUK. 2012. $\quad$ www.rcuk.ac.uk/RCUKprod/assets/documents/publications/RCUKFrameworkforCapitalInvestment2012.pdf Accessed 13 August $\underline{2015 .}$ 
52 Wilson T. A Review of Business-University Collaboration. 2012. www.gov.uk/government/uploads/system/uploads/attachment data/file/32383/12-610-wilson-reviewbusiness-university-collaboration.pdf Accessed 13 August 2015.

53 Chandras C, Weaver T, Zouberakis M, Smedley D, Schughart K, Rosenthal N, Hancock JM, Kollias G, Schofield PN, Aidinis V. Models for financial sustainability of biological databases and resources. Database.Vol. 2009, Article ID bap017, doi:10.1093/database/bap017.

54 N8 Research Capital Operational Infrastructure Group. N8 Sharing For Excellence And Growth Phase Ii: The N8 Equipment Sharing Toolkit $\quad$ (N8 $\quad$ EST). 2014. http://www.n8research.org.uk/assets/files/Documents/N8\%20Equipment\%20Sharing\%20Toolkit/N8\%20r eport.pdf Accessed 13 August 2015.

55 UK Biobank Access procedures: Application and review procedures for access to the UK Biobank Resource. www.ukbiobank.ac.uk/scientists-3/using-the-genetic-data/ Accessed 13 August 2015.

56 Bravo E, Calzolari A, De Castro P, Mabile L, Napolitani F, Rossi A M, Cambon-Thomsen A. Developing a guideline to standardize the citation of bioresources in journal articles (CoBRA) BMC Medicine 2015, 13:33 doi:10.1186/s12916-015-0266-y

57 Wichmann HE, Kuhn KA, Waldenberger M, Schmelcher D, Schuffenhauer S, Meitinger T, Wurst S, Lamla G, Fortier I, Burton PR, Peltonen L, Metspalu A, Riegman P, Landegren U, Taussig M, Litton J-E, Fransson M, Eder J, Cambon-Thomsen A, Bovenberg J, Dagher G, van Ommen GJ, Griffith M, Yuille M, Zatloukal K. Comprehensive catalogue of European biobanks. Nature Biotechnology 2011; 29;795-797. 21904320

58 Bresnahan TF. Measuring the spillovers from technical advance: mainframe computers in financial services. American Economic Review. 1986;76:742-755. 
59 Jaffe AB. Technological opportunity and spillovers of R\&D: evidence from firms' patents, profits, and market value. American Economic Review. 1986;76:984-1001.

60 Tassey G. The Roles and Economic Impacts of Technology Infrastructure. 2008. http://www.nist.gov/director/planning/upload/Measurement_Infrastr_Roles_Impacts_v3.pdf Accessed 13 August 2015.

61 Lester R. Universities, innovation and the competitiveness of local economies: a summary report from the local innovation system project: Phase 1. 2005. Massachusetts Institute of Technology, Cambridge. http://web.mit.edu/lis/papers/LIS05-010.pdf Accessed 13 August 2015.

62 OECD. Knowledge networks and markets in the life sciences. 2012. OECD Publishing. Accessed: http://dx.doi.org/10.1787/9789264168596-en Accessed 13 August 2015.

63 Biobanks worry specimens will go to waste http://www.futurity.org/health-medicine/biobanks-worryspecimens-will-go-to-waste/ Accessed 13 August 2015.

64 Transaction costs comprise all the costs (other than the price) that are incurred during economic transactions such as search costs or information processing.

65

STRATUM Exploitation

Plan

http://stratumbiobanking.org/docs/Exploitation\%20Plan\%20STRATUM\%20Final_version\%201_\%20160 82013.pdf Accessed 13 August 2015.

66 HTA Codes of practice https://www.hta.gov.uk/codes-practice Accessed 13 August 2015.

67 Bromley RL. Financial Stability in Biobanking: Unique Challenges for Disease-Focused Foundations and Patient Advocacy Organizations Biopreservation and Biobanking. October 2014, 12(5): 294-299. 
68 Barnes RO, Schacter B, Kodeeswaran S, CTRNet Management Committee, Watson PH. Funding Sources for Canadian Biorepositories: The Role of User Fees and Strategies to Help Fill the Gap. Biopreservation and Biobanking. October 2014, 12(5): 300-305.

69 Wilson GD, D'Angelo K, Pruetz BL, Geddes TJ, Larson DM, Akervall J. The Challenge of Sustaining a Hospital-Based Biobank and Core Molecular Laboratory: The Beaumont Experience Biopreservation and Biobanking. October 2014, 12(5): 306-311.

70 Matharoo-Ball B, Thomson BJ. Nottingham Health Science Biobank: a Sustainable Bioresource. Biopreservation and Biobanking. October 2014, 12(5): 312-316.

71 Albert M, Bartlett J, Johnston RN, Schacter B, Watson P. Biobank Bootstrapping: Is Biobank Sustainability Possible Through Cost Recovery? Biopreservation and Biobanking. December 2014, 12(6): 374-380.

72 Parry-Jones A. Assessing the Financial, Operational, and Social Sustainability of a Biobank: The Wales Cancer Bank Case Study. Biopreservation and Biobanking. December 2014, 12(6): 381-388.

73 Warth R, Perren A. Construction of a Business Model to Assure Financial Sustainability of Biobanks. Biopreservation and Biobanking. December 2014, 12(6): 389-394.

74 Carpenter JE, Clarke CL. Biobanking Sustainability_Experiences of the Australian Breast Cancer Tissue Bank (ABCTB). Biopreservation and Biobanking. December 2014, 12(6): 395-401.

75 Innovate UK. www.gov.uk/government/organizations/innovate-uk Accessed 13 August 2015.

76 Technology Strategy Board. Stratified medicines programme: Developing business models and value systems. 2011. https://connect.innovateuk.org/documents/2843120/3724280/Stratified+Medicine+Innovation+Platform+i nformation.pdf/3a8aa58d-4f18-4ede-92b2-07da32bf5663 Accessed 13 August 2015. 